\title{
Stakeholder salience and social responsibility: Study of small businesses in Malaysia
}

\author{
Completed Research Paper
}

\author{
Mehran Nejati \\ Graduate School of Business, \\ Universiti Sains Malaysia (USM), \\ Penang 11800, Malaysia \\ Noor Hazlina Ahmad \\ School of Management, \\ Universiti Sains Malaysia (USM), \\ Penang 11800, Malaysia
}

\author{
Azlan Amran \\ Graduate School of Business, \\ Universiti Sains Malaysia (USM), \\ Penang 11800, Malaysia
}

\begin{abstract}
This study empirically examined the role of stakeholders' influence on social responsibility practices of small businesses in Malaysia, and analysed the importance and current attention of small firms to these stakeholder groups using the Importance-Performance Matrix Analysis (IPMA). Findings of this study revealed that community's influence and customers' influence had significant positive impact on the social responsibility practices of small firms. Moreover, the results of IPMA for the social responsibility construct indicated that community's influence had the highest importance for small businesses and was given the highest level of attention by the firms. In contrast, customer's influence was given lower attention by small firms despite its high level of importance for social responsibility practices of the firm.
\end{abstract}

Keywords: Social responsibility, Stakeholder relations, Small business, Importance-Performance Matrix Analysis (IPMA), Malaysia.

\section{Introduction}

Following McWilliams and Siegel (2001), corporate social responsibility (CSR) is defined as actions undertaken by the firm which advance some social good, beyond the immediate interests of the firm and its shareholders and beyond what is required by law. The CSR journey that started centuries ago is still growing at an unprecedented pace with no sign of slowing down (Nejati, Quazi, \& Amran, 2015). The increasing attention to CSR has been partly caused by the growing level of awareness and salience on the social responsibilities of organizations. While over 50 definitions of stakeholder have been offered since 1963 (Friedman \& Miles, 2006), it often refers to "any group or individual who can affect or is affected by the achievement of the organization objectives" (Freeman, 1984, p. 46).

According to stakeholder theory, stakeholders can influence social practices of a firm. Moreover, based on institutional theory firms are surrounded by formal and informal institutions (North, 1990). The formal institutions comprise of national legislation and government regulation, whereas the informal institutions consist of cognitive issues (e.g., norms, conventions and shared beliefs). As a result of these formal and informal institutions, 
small firms are come under various social and cultural pressures to comply with their institutional environments for achieving legitimacy and social fitness (Scott, 1995). Therefore, small firms should respond to these pressures and adequately embed in the local society to ensure their business sustainability and continued growth. This can be achieved through accommodating the demands of key stakeholders.

Earlier studies have investigated the role of stakeholders on CSR (Perez-Batres, Doh, Miller, \& Pisani, 2012). However, the individual role of each stakeholder group on social responsibility practices of small firms has rarely been investigated (Nejati, Amran, \& Hazlina Ahmad, 2014; Park \& Ghauri, 2014). Furthermore, according to Bourne (2009), a balanced view of success for organizations requires a balanced combination of delivering value, managing relationships and managing risks. This highlights the necessity of managing key stakeholders and commitment to firm's social responsibilities to minimize and manage risks. Thus, this study aims to elucidate the role of stakeholder salience on social responsibility of small firms by answering the following question: Does stakeholder salience influence social responsibility practices of small firms?

The stakeholder salience will be measured by the influence of each stakeholder group on small firms toward practicing social and environmental behaviours. It is also of paramount importance for organizations to accurately determine the relevance of each stakeholder group (Henriques \& Sadorsky, 1999; Perez-Batres, Miller, \& Pisani, 2010). Thus, we will examine the importance-performance index for the social responsibility practices and identify the most important and influential stakeholder groups for small businesses in Malaysia, while determining the current performance of the firms in addressing their demands.

According to Small and Medium Industries Development Corporation (SMIDEC), Malaysian small businesses account for 27.3 percent of total manufacturing output, 25.8 percent of value-added production, and 27.6 percent of fixed assets in the country. In addition, value-added products from small and medium-sized enterprises (SMEs) are expected to be worth RM 120 billion - or 50 percent of total production - in the manufacturing sector by 2020 (Saleh \& Ndubisi, 2006; SMIDEC., 2002). Besides, in the service sector, according to the Department of Statistics (DOS) by the year 2006 in Malaysia, there were 192,527 establishments in the services sector, and 186,728 (or 96.7 percent) of these were made up of small firms. Given the significant scale of small businesses in Malaysian economy, their aggregate achievements have a major impact on the country's success. Moreover, their operations, in total, have great impacts on society and environment.

\section{Social Responsibility and Small Firms}

Although the issue of corporate social responsibility has been mainly associated with large firms, there has been a shift in perception towards the social responsibilities of small businesses caused by the recognition of their growing significance (Azmat \& Samaratunge, 2009). Recognition of the growing significance of the small firms (Fuller, 2003) has resulted in an emphasis on their social and environmental impacts. Apart from their significant contributions towards job creation and economic prosperity of their country, small businesses are thought to have considerable environmental impacts by accounting for $60 \%$ of all carbon dioxide emissions and 70\% of all pollution (Parker, Redmond, \& Simpson, 2009).

Beliefs and attitudes regarding the nature of CSR have varied over time (Hill, Stephens, \& Smith, 2003) with most recent definitions describing CSR through the lens of stakeholder theory (Jones, 2005; Sweeney, 2007; Vos, 2003). Bowmann-Larsen and Wiggen (2004) defined stakeholders as all those individuals and groups with a 'critical eye' on corporate actors. Stakeholder theory offers a new way to organize thinking about the responsibilities of 
a firm (Jamali, 2008). Since stakeholders hold the power over the resources required by small businesses, it is crucial for firms to get the approval of stakeholders and adjust their activities to ensure that such an approval is obtained (Zain, 2009). Gadenne, Kennedy, and McKeiver (2009) examined the influence of various stakeholders on the awareness and attitudes of SME owners and its relation to actions taken within the businesses to reduce the environmental impact of their operations. They found that supplier and legislation had significant influences, whereas customer influence was not significant.

Earlier studies have indicated that small businesses experience more difficulty to engage in social responsibility initiatives. As Hitchens, Thankappan, Trainor, Clausen, and De Marchi (2005) discussed, many small business owners/managers have never thought about CSR or even believed that their social and environmental impacts are negligible. Besides, several small business managers argue that they do not have time or resources to dedicate to social responsibility (BITC, 2002; Observatory of European SMEs, 2002).

It is argued that majority of small businesses are simply content to survive (Baker, 2003). Since social responsibility is increasingly seen as a vital factor in the long-term survival of companies (Khan, Halabi, \& Samy, 2009), small businesses can involve in responsible business behaviours to establish a better relationship with their key stakeholders and ensure their survival. This is crucial to small businesses since relationships with stakeholders mean everything to them (Fuller \& Lewis, 2002). Murillo and Lozano (2006) supported the use of stakeholder theory as a helpful theoretical framework within which small businesses are able to make sense of their activities. This selection is grounded in the belief that the relationship between firm and stakeholders is an essential asset that managers must manage (Post, Preston, \& Sachs, 2002). Stakeholders encourage firms to practice social responsibility (Nejati \& Amran, 2009), and responsible behaviours towards stakeholders can lead to establishing trust links between firm and the stakeholders (Battaglia, Bianchi, Frey, \& Iraldo, 2010). Therefore, in line with stakeholder theory, small businesses are expected to engage in social responsibility practices as a way to respond to their stakeholder demands. To this end, the salience level of stakeholders and the perceived importance of each stakeholder group are likely to influence firm's social responsibility. Thus, we hypothesize that stakeholders' influence positively influences social responsibility practices of small firms.

\section{Methods}

The data for this study was collected using surveys distributed among small businesses in Malaysia, randomly selected from the directory of small businesses in Malaysia (SMEinfo). From the 350 distributed questionnaires, 148 responses were collected representing 42\% response rate. Participating firms were mainly from manufacturing, construction, logistics, retail, and information technology sector. This study used the definition of SMEs given by SME Corp (2012), which defines SMEs as firms with less than 150 employees in manufacturing sector and less than 50 employees in the service sector, which is consistent with other definitions of SMEs in different contexts (Australian Bureau of Statistics, 2002). Stakeholders' influence was measured using items adapted from the study by Gadenne et al. (2009), whereas social responsibility was measured from the construct by Spiller (2000).

This study applied Partial Least Squares (PLS) Structural Equation Modelling to analyse the data, due to having a formative construct (i.e. social responsibility) in the study. Moreover, PLS is able to accommodate smaller sample size better than Covariance BasedSEM (Chin \& Newsted, 1999; Hsu, Chen, \& Hsieh, 2006) in terms of its ability to generate predictive accuracy. This study performed Harman's single factor test (Podsakoff, MacKenzie, Lee, \& Podsakoff, 2003) to assess the presence of common method bias, and it 
did not appear to be a pervasive problem in the current study. Additionally, the sample size adequacy was confirmed through using G*Power 3.1.3 software (Faul, Erdfelder, Lang, \& Buchner, 2007).

PLS path modelling was performed in two steps. First, the measurement model was evaluated and confirmed (Figure 1). Then, structural model was evaluated for examining the proposed research paths. Table 1 presents the assessment of the measurement model in terms of convergent validity and reliability.

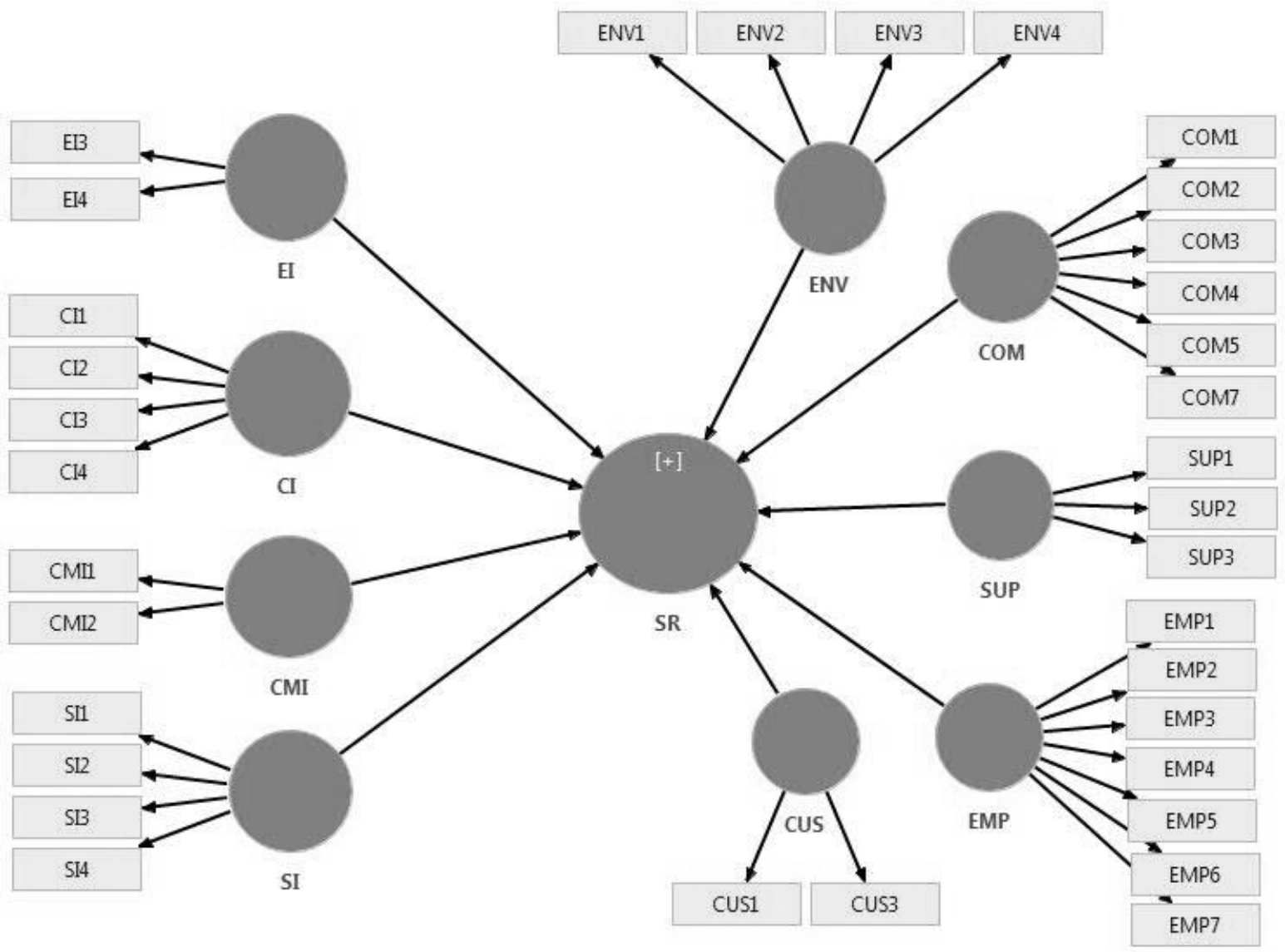

Figure 1: Measurement model in SmartPLS

Table 1: Item loadings, AVE, composite reliability (CR) for reflective constructs and weights, VIF, t-value for the formative construct

\begin{tabular}{lccccc}
\hline Construct Scale & Measurement Model & Item & Loadings & AVE & CR \\
\hline Employees' Influence (EI) & Reflective & EI3 & 0.798 & 0.733 & 0.845 \\
& & EI4 & 0.910 & & \\
Customers' Influence (CI) & Reflective & CI1 & 0.865 & 0.831 & 0.952 \\
& & CI2 & 0.942 & & \\
& & CI3 & 0.934 & & \\
Community's Influence & Reflective & CI4 & 0.903 & & \\
(CMI) & & CMI2 & 0.960 & 0.905 & 0.950 \\
Suppliers' Influence (SI) & Reflective & SI1 & 0.931 & 0.913 & 0.977 \\
& & SI2 & 0.959 & &
\end{tabular}




\begin{tabular}{|c|c|c|c|c|c|}
\hline & & SI4 & 0.964 & & \\
\hline Responsibility toward & Reflective & ENV1 & 0.757 & 0.674 & 0.892 \\
\hline \multirow[t]{3}{*}{ Environment (ENV) } & ( $1^{\text {st }}$ Order $)$ & ENV2 & 0.815 & & \\
\hline & & ENV3 & 0.832 & & \\
\hline & & ENV4 & 0.876 & & \\
\hline \multirow{6}{*}{$\begin{array}{l}\text { Responsibility toward } \\
\text { Community (COM) }\end{array}$} & Reflective & COM1 & 0.899 & 0.597 & 0.897 \\
\hline & ( $1^{\text {st }}$ Order $)$ & COM2 & 0.787 & & \\
\hline & & COM3 & 0.708 & & \\
\hline & & COM4 & 0.801 & & \\
\hline & & COM5 & 0.842 & & \\
\hline & & COM7 & 0.552 & & \\
\hline \multirow{3}{*}{$\begin{array}{l}\text { Responsibility toward } \\
\text { Suppliers (SUP) }\end{array}$} & Reflective & SUP1 & 0.778 & 0.670 & 0.859 \\
\hline & ( $1^{\text {st }}$ Order) & SUP2 & 0.799 & & \\
\hline & & SUP3 & 0.875 & & \\
\hline \multirow{7}{*}{$\begin{array}{l}\text { Responsibility toward } \\
\text { Employees (EMP) }\end{array}$} & Reflective & EMP1 & 0.730 & 0.586 & 0.908 \\
\hline & ( $1^{\text {st }}$ Order $)$ & EMP2 & 0.765 & & \\
\hline & & EMP3 & 0.772 & & \\
\hline & & EMP4 & 0.789 & & \\
\hline & & EMP5 & 0.696 & & \\
\hline & & EMP6 & 0.795 & & \\
\hline & & EMP7 & 0.806 & & \\
\hline \multirow{3}{*}{$\begin{array}{l}\text { Responsibility toward } \\
\text { Customers (CUS) }\end{array}$} & Reflective & CUS1 & 0.852 & 0.627 & 0.770 \\
\hline & $\left(1^{\text {st }}\right.$ Order $)$ & CUS3 & 0.726 & & \\
\hline & & & Weights & VIF & T-Value \\
\hline \multirow[t]{5}{*}{ Social Responsibility } & Formative & ENV & 0.258 & 1.944 & $9.460 * *$ \\
\hline & & $\mathrm{COM}$ & 0.377 & 2.438 & $11.707 * *$ \\
\hline & & SUP & 0.111 & 1.262 & $5.619 * *$ \\
\hline & & EMP & 0.424 & 2.555 & $11.340 * *$ \\
\hline & & CUS & 0.106 & 1.857 & $9.554 * *$ \\
\hline
\end{tabular}

$* \mathrm{p}<0.05 ; * * \mathrm{p}<0.01$

The discriminant validity of the measurement model for reflective constructs was confirmed through evaluation of the heterotrait-monotrait ratio of correlations (HTMT) proposed by (Henseler, Ringle, \& Sarstedt, 2014). Results of the HTMT approach (Table 2) verified the discriminant validity of the model as all ratio were below the conservative threshold of 0.85 (Clark \& Watson, 1995; Kline, 2011).

Table 2: Discriminant validity of reflective constructs

\begin{tabular}{ccccc}
\hline & EI & CI & CMI & SI \\
\hline EI & & & & \\
CI & 0.78 & & & \\
CMI & 0.57 & 0.55 & & \\
SI & 0.20 & 0.34 & -0.04 & \\
\hline
\end{tabular}




\section{Findings and Conclusion}

This study found that among the four major stakeholder groups investigated (employees, customers, community and suppliers) only community and customers had a significant positive influence on the social practices of the firm (Table 3). Since small firms operate in a small local community, establishing and maintaining a good relationship with key stakeholders plays an important role in ensuring firm's survival. Hence, customers and suppliers are found to have a significant and influential stakeholder group for small firms.

Table 3: Results of path modelling

\begin{tabular}{lccc}
\hline Relationship & Path Coefficient & t-value & Decision \\
\hline EI $\rightarrow$ SR & 0.139 & 1.393 & Not Supported \\
CI $\rightarrow$ SR & 0.230 & $1.901^{*}$ & Supported \\
CMI $\rightarrow$ SR & 0.242 & 1.584 & Not Supported \\
SI $\rightarrow$ SR & 0.201 & $2.519^{* *}$ & Supported \\
\hline
\end{tabular}

$* \mathrm{p}<0.05 ; * * \mathrm{p}<0.01$

To further investigate the results of the structural model, importance-performance matrix analysis of path modelling for social responsibility was carried out. IPMA results indicate the areas which need to be paid attention and improved with management activities (Hock, Ringle, \& Sarstedt, 2010). In particular, by measuring the total effect (i.e. importance) and index values of the latent variables (i.e. performance), the latent variables with a relatively high importance and relatively low performance on a particular endogenous latent variable would be identified to provide managerial insights (Hock et al., 2010; Schloderer, Sarstedt, \& Ringle, 2014). Accordingly, in this study, importance and performance of the latent exogenous variables (i.e., employees' influence, customers' influence, community's influence and suppliers' influence) on the endogenous variable (i.e. social responsibility) was measured. The results are illustrated in Table 4 and visualized in Figure 2.

Table 4: Total effects and index values

\begin{tabular}{lcc}
\hline & \multicolumn{2}{c}{ Social Responsibility } \\
\cline { 2 - 3 } Latent Variable & Total Effect (Importance) & Index value (Performance) \\
\hline Employees' Influence & 0.139 & 64.522 \\
Customers' Influence & 0.230 & 64.458 \\
Community's Influence & 0.242 & 82.014 \\
Suppliers' Influence & 0.201 & 65.471 \\
\hline
\end{tabular}




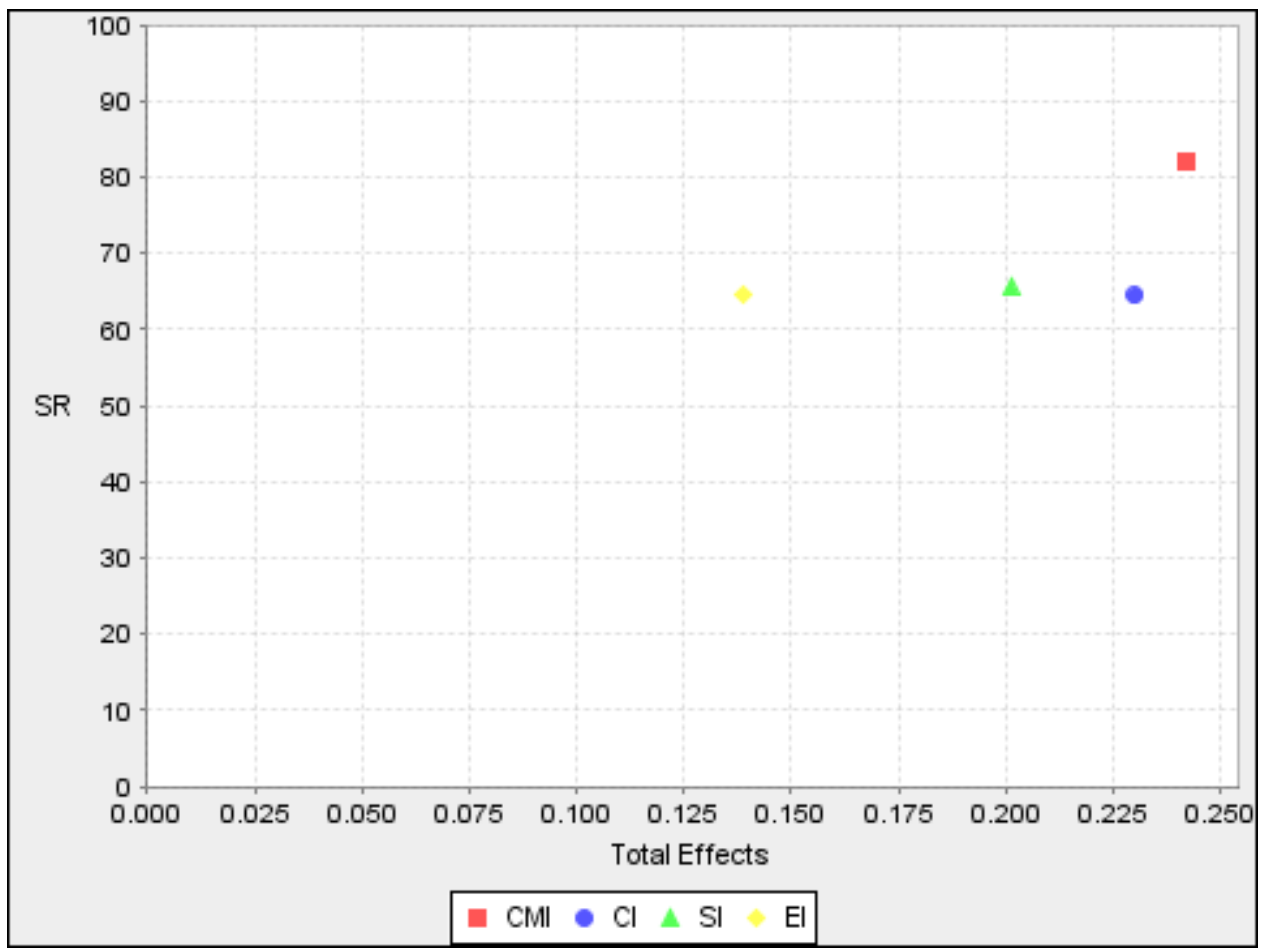

Figure 2: Importance-Performance Matrix Analysis (IPMA) for social responsibility construct

As depicted in the importance-performance matrix analysis map, the highest level of importance belongs to community's influence, followed by customers' influence, suppliers' influence and employees' influence. Besides, among the four antecedents of social responsibility, community's influence has the highest performance which indicates that firms pay their highest attention to the community and their demands in addressing the firm's social responsibilities. However, customers' influence which is the second priority for firms has a relatively low performance and requires more attention by small businesses. These findings provide insights to small businesses in Malaysia to not only focus on community aspect, but also engage their other important stakeholders, specifically customers, in planning and practicing their social responsibilities.

Despite the growing interest in the social responsibility of companies, small firms have been under-researched and no areas of research into CSR and SMEs can be claimed to be well undertaken (Moore \& Spence, 2006). Results of this study revealed that stakeholders' influence could predict $33 \%$ of variation in the social responsibility practices of small firms (R-Square $=0.33$ ). Findings of this study are in line with the stakeholder theory and corroborated earlier studies which indicated the influence of stakeholders in social responsibility practices of companies (Coppa \& Sriramesh, 2013; Figar \& Figar, 2011; Morsing, 2006). Results are also consistent with earlier studies which indicate that maintaining a good reputation among neighbours and community is very crucial for small businesses (Fitjar, 2011). Additionally, earlier studies in Malaysia had also shown that employees and customers were among the most important dimensions of social responsibility by Malaysian SMEs (Irawati, Nejati, Amran, \& Shafaei, 2012). The current study confirmed the significant role of customers along with suppliers in encouraging responsible practices by small businesses. This can be contributed to the dependence of small businesses to these groups, as well as the necessity of dealing personally with customers and suppliers (Spence, 1999), and thus the need for maintaining good relations with these stakeholder groups.

This study is limited by its sample size. Nonetheless, previous literature states that this is a common phenomenon in SME research and obtaining a large sample size from small 
businesses is very difficult. Future studies may investigate the impact of responsible practices by small businesses on their relationship with stakeholders.

\section{Acknowledgement}

This research was supported by USM Short Term Grant (\# 304/PPAMC/6313173).

\section{References}

Australian Bureau of Statistics, . (2002). Generosity of Australian businesses. Canberra: AGPS.

Azmat, Fara, \& Samaratunge, Ramanie. (2009). Responsible entrepreneurship in developing countries: understanding the realities and complexities. Journal of Business Ethics, 90(3), 437-452.

Baker, M. (2003). Doing It Small. Ethical Corporation Magazine(August 20th).

Battaglia, Massimo, Bianchi, Lara, Frey, Marco, \& Iraldo, Fabio. (2010). An innovative model to promote CSR among SMEs operating in industrial clusters: evidence from an EU project. Corporate Social Responsibility and Environmental Management, 17(3), 133-141.

BITC. (2002). Engaging SMEs in Community and Social Issues. London: Business in the Community.

Bourne, Lynda. (2009). Stakeholder Relationship Management: A Maturity Model for Organisational Implementation. Farnham: Gower Publishing, Ltd.

Bowmann-Larsen, L., \& Wiggen, O. (2004). Responsibility in World Business: Managing Harmful Side-Effects of Corporate Activity. USA: United Nations University Press.

Chin, W.W., \& Newsted, P.R. (1999). Structural equation modeling analysis with small samples using partial least squares. Statistical strategies for small sample research, 2, 307-342.

Clark, Lee Anna, \& Watson, David. (1995). Constructing validity: Basic issues in objective scale development. Psychological assessment, 7(3), 309.

Coppa, Marcello, \& Sriramesh, Krishnamurthy. (2013). Corporate social responsibility among SMEs in Italy. Public Relations Review, 39(1), 30-39.

Faul, Franz, Erdfelder, Edgar, Lang, Albert-Georg, \& Buchner, Axel. (2007). G* Power 3: A flexible statistical power analysis program for the social, behavioral, and biomedical sciences. Behavior research methods, 39(2), 175-191.

Figar, Nadica, \& Figar, Vladimir. (2011). Corporate social responsibility in the context of the stakeholder theory. Facta universitatis-series: Economics and Organization, 8(1), 113.

Fitjar, Rune Dahl. (2011). Little big firms? Corporate social responsibility in small businesses that do not compete against big ones. Business Ethics: A European Review, 20(1), 3044.

Freeman, R. E. (1984). Strategic Management: A Stakeholder Approach. Boston, MA: Pitman.

Friedman, Andrew L, \& Miles, Samantha. (2006). Stakeholders: Theory and Practice. Oxford: Oxford University Press.

Fuller, T. (2003). Small business futures in society. Futures, 35(4), 297-304.

Fuller, T., \& Lewis, J. (2002). 'Relationships Mean Everything'; A Typology of SmallBusiness Relationship Strategies in a Reflexive Context. British Journal of Management, 13(4), 317-336. 
Gadenne, David L, Kennedy, Jessica, \& McKeiver, Catherine. (2009). An empirical study of environmental awareness and practices in SMEs. Journal of Business Ethics, 84(1), 45-63.

Henriques, Irene, \& Sadorsky, Perry. (1999). The relationship between environmental commitment and managerial perceptions of stakeholder importance. Academy of management Journal, 42(1), 87-99.

Henseler, Jörg, Ringle, Christian M, \& Sarstedt, Marko. (2014). A new criterion for assessing discriminant validity in variance-based structural equation modeling. Journal of the Academy of Marketing Science, 1-21.

Hill, R., Stephens, D., \& Smith, I. (2003). Corporate social responsibility: an examination of individual firm behaviour. Business and Society Review, 108(3), 339-364.

Hitchens, David, Thankappan, Samarthia, Trainor, Mary, Clausen, Jens, \& De Marchi, Bruna. (2005). Environmental performance, competitiveness and management of small businesses in Europe. Tijdschrift voor economische en sociale geografie, 96(5), 541557.

Hock, Claudia, Ringle, Christian M, \& Sarstedt, Marko. (2010). Management of multipurpose stadiums: Importance and performance measurement of service interfaces. International Journal of Services Technology and Management, 14(2), 188-207.

Hsu, S.H., Chen, W., \& Hsieh, M. (2006). Robustness testing of PLS, LISREL, EQS and ANN-based SEM for measuring customer satisfaction. Total Quality Management \& Business Excellence, 17(3), 355-372.

Irawati, D., Nejati, M., Amran, A., \& Shafaei, A. (2012). Investigating Malaysian SMEs in CSR Agenda: Perspective from Developing Region in ASEAN. Paper presented at the Regional Studies Association European Conference, Delft, The Netherlands.

Jamali, Dima. (2008). A stakeholder approach to corporate social responsibility: A fresh perspective into theory and practice. Journal of business ethics, 82(1), 213-231.

Jones, Marc T. (2005). The transnational corporation, corporate social responsibility and the'outsourcing'debate. Journal of the American academy of business, Cambridge, 6(2), 91-97.

Khan, Md Habib-Uz-Zaman, Halabi, Abdel K, \& Samy, Martin. (2009). Corporate social responsibility (CSR) reporting: a study of selected banking companies in Bangladesh. Social Responsibility Journal, 5(3), 344-357.

Kline, R. B. (2011). Principles and practice of structural equation modeling. New York: Guilford Press.

McWilliams, Abagail, \& Siegel, Donald. (2001). Corporate social responsibility: A theory of the firm perspective. Academy of management review, 26(1), 117-127.

Moore, Geoff, \& Spence, Laura. (2006). Editorial: Responsibility and small business. Journal of Business Ethics, 67(3), 219-226.

Morsing, Mette. (2006). Drivers of corporate social responsibility in SMEs. Paper presented at the International Conference on CSR in Small and Medium Sized Enterprises.

Murillo, D., \& Lozano, J.M. (2006). SMEs and CSR: An approach to CSR in their own words. Journal of Business Ethics, 67(3), 227-240.

Nejati, Mehran, \& Amran, Azlan. (2009). Corporate social responsibility and SMEs: exploratory study on motivations from a Malaysian perspective. Business strategy series, 10(5), 259-265.

Nejati, Mehran, Amran, Azlan, \& Hazlina Ahmad, Noor. (2014). Examining stakeholders' influence on environmental responsibility of micro, small and medium-sized enterprises and its outcomes. Management Decision, 52(10), 2021-2043.

Nejati, Mehran, Quazi, Ali, \& Amran, Azlan. (2015). Corporate Social Responsibility and Sustainability: Contemporary Perspectives. Kuala Lumpur: Pearson. 
North, D. (1990). Institutions, institutional change and economic performance. Cambridge: Cambridge University Press.

Observatory of European SMEs. (2002). European SMEs and Social and Environmental Responsibility. Luxembourg: Office for Official Publications of the European Communities.

Park, Byung Il, \& Ghauri, Pervez N. (2014). Determinants influencing CSR practices in small and medium sized MNE subsidiaries: A stakeholder perspective. Journal of World Business.

Parker, Craig, Redmond, Janice, \& Simpson, Mike. (2009). Review of interventions to encourage SMEs to make environmental improvements. Environment and planning $C$ : Government \& policy, 27(2), 279-301.

Perez-Batres, Luis A, Doh, Jonathan P, Miller, Van V, \& Pisani, Michael J. (2012). Stakeholder pressures as determinants of CSR strategic choice: Why do firms choose symbolic versus substantive self-regulatory codes of conduct? Journal of business ethics, 110(2), 157-172.

Perez-Batres, Luis A, Miller, Van V, \& Pisani, Michael J. (2010). CSR, sustainability and the meaning of global reporting for Latin American corporations. Journal of Business Ethics, 91(2), 193-209.

Podsakoff, Philip M, MacKenzie, Scott B, Lee, Jeong-Yeon, \& Podsakoff, Nathan P. (2003). Common method biases in behavioral research: a critical review of the literature and recommended remedies. Journal of applied psychology, 88(5), 879.

Post, James E., Preston, Lee E, \& Sachs, Sybille. (2002). Managing the Extended Enterprise: The New Stakeholder View. California Management Review, 45(1), 6-28.

Saleh, Ali Salman, \& Ndubisi, Nelson Oly. (2006). An evaluation of SME development in Malaysia. International Review of Business Research Papers, 2(1), 1-14.

Schloderer, Matthias P, Sarstedt, Marko, \& Ringle, Christian M. (2014). The relevance of reputation in the nonprofit sector: the moderating effect of socio-demographic characteristics. International Journal of Nonprofit and Voluntary Sector Marketing, 19(2), 110-126.

Scott, W. R. (1995). Institutions and organizations. London: Sage Publications.

SME Corp. (2012). Definition of SMEs. Retrieved March 28, 2012, from http://www.smecorp.gov.my/v4/node/14

SMIDEC. (2002). SMI Development Plan (2001-2005). Kuala Lumpur: Percetakan Nasional Malaysia Berhad.

Spence, Laura J. (1999). Does size matter? The state of the art in small business ethics. Business ethics: a European review, 8(3), 163-174.

Spiller, Rodger. (2000). Ethical business and investment: A model for business and society: Springer.

Sweeney, Lorraine. (2007). Corporate social responsibility in Ireland: barriers and opportunities experienced by SMEs when undertaking CSR. Corporate governance, 7(4), 516-523.

Vos, Janita FJ. (2003). Corporate social responsibility and the identification of stakeholders. Corporate Social Responsibility and Environmental Management, 10(3), 141-152.

Zain, M.M. (2009). Professional Lecture: Corporate Social Responsibility in Malaysia. Shah Alam: University Publication Centre (UPENA). 